\title{
Ambulatory small intestinal motility in 'diarrhoea' predominant irritable bowel syndrome
}

\author{
D A Gorard, G W Libby, M J G Farthing
}

\begin{abstract}
Dysmotility of the duodenum and proximal jejunum has been reported in patients with irritable bowel syndrome. This study extended these findings by recording fasting ambulatory motility from electronic strain gauge sensors sited in the jejunum and ileum of eight diarrhoea predominant irritable bowel syndrome patients and 12 healthy controls. During the day, periodicity of migrating motor complexes mean (SEM) did not differ between patients (92 (10) $\mathrm{min}$ ) and controls (85 (7) $\mathrm{min})$. At night, periodicity was shorter in both patients and controls, and the daytime dominance of phase II was replaced by phase I. In both groups, aboral progression of phase III fronts was associated with a slowing of propagation velocity and maximum contractile rate, but an increase in mean amplitude of contraction. Discrete clustered contractions were seen in seven patients and 10 controls occupying 14 and $16 \%$ of daytime phase II activity, respectively. Pain episodes were not associated with any specific motility patterns. Despite the lack of motility differences between the two groups, orocaecal transit time in the irritable bowel syndrome patients was shorter at $57(9) \mathrm{min}$ than in the controls, $82(6) \mathrm{min}(\mathrm{p}<0.05)$. This ambulant study has failed to show any abnormalities of fasting small intestinal motility that might distinguish diarrhoea predominant irritable bowel syndrome patients from healthy controls.
\end{abstract}

(Gut 1994; 35: 203-210)

Irritable bowel syndrome (IBS) is characterised by abdominal pain, disturbed defecation, and abdominal bloating in the absence of any structural or biochemical abnormality. Although the pathophysiology of IBS remains unclear, it is widely believed that IBS is commonly associated with disordered gastrointestinal motility. Many IBS symptoms involve disturbances of defecation, and most attention has been focused on motility of the colon and rectum. Studies of colonic motor activity in IBS have suggested various motility abnormalities but these features are not consistent. ${ }^{2}$ Difficulties in defining normal colonic motor physiology contribute to the discrepancies.

Abdominal symptoms in IBS may originate from organs other than the colon. ${ }^{34}$ The small intestine has been studied as a site of possible dysmotility. In contrast with the colon, normal patterns of motility are more clearly defined in the small intestine, ${ }^{5-9}$ although there is considerable variability in health. ${ }^{10}{ }^{11}$ During fasting the small intestine exhibits a distally migrating cycle of motility, the interdigestive migrating motor complex (MMC). ${ }^{12-14}$ This pattern is promptly disrupted by ingestion of food and replaced by irregular contractile activity. During prolonged recordings of small intestinal motility in IBS, abnormalities of MMC cycle length and the presence of abnormal motor patterns temporarily associated with symptoms have been described. ${ }^{15-18}$ Such abnormalities have been identified in the fasting state. These prolonged recordings have been obtained in stationary subjects using water perfused catheters spanning the whole small intestine ${ }^{16}$ or limited to the duodenojejunal flexure,,$^{18}$ and in ambulant subjects using pressure sensitive radiotelemetric capsules $^{15}$ or electronic strain gauges ${ }^{17}$ spanning only the duodenojejunal flexure.

The aim of this study was to record fasting intestinal motility from sites spanning the jejunum and proximal ileum in ambulant IBS patients and healthy volunteers, and to measure small intestinal transit times in these same subjects. Because of the heterogeneity of IBS symptoms and the possibility that different symptom patterns might be associated with specific motility disturbances ${ }^{4619-21}$ we reasoned that any abnormalities of motility were more likely to come to light if a specific symptom group were examined. We chose to investigate IBS patients who were particularly troubled by increased frequency of defecation ('diarrhoea predominant').

\section{Methods}

\section{SUBJECTS}

Eight patients (four men, four women, mean age 36 years, range 24-53) attending the gastroenterology clinic with a diagnosis of IBS $^{22} 23$ were studied. All complained of 'diarrhoea' as their predominant bowel habit and were selected because of the severity of their symptoms. These patients had a median of 4 (range 3-6) bowel actions/day. In addition to urgency and frequency of defecation, loose stools, and incomplete rectal evacuation, all patients were troubled by abdominal pain. All patients had at times been sufficiently incapacitated by their defecatory symptoms to have time off work and two had had to change their jobs. All patients had a normal full blood count, plasma biochemistry, sigmoidoscopy, rectal biopsy, and barium enema. Barium follow through, colonoscopy with biopsies, jejunal biopsy, and lactose tolerance test were also performed in some patients when considered to be clinically appropriate. None of the patients had had gastrointestinal surgery and none had taken any drugs for at least two weeks before the study.

Twelve healthy volunteers (seven men, five 


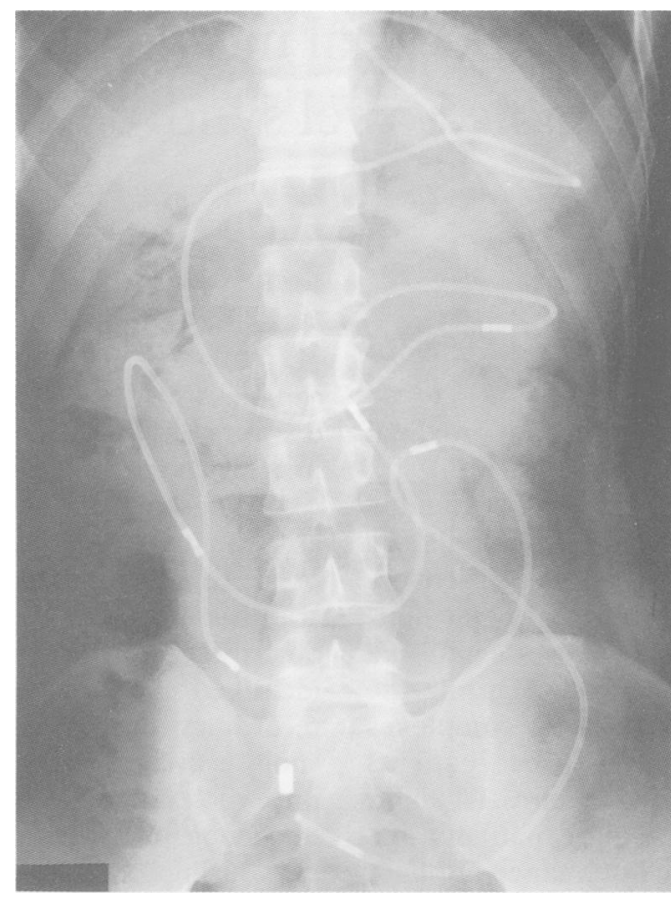

Figure 1: Plain abdominal radiograph showing catheter with six solid state pressure transducers sited from the duodenojejunal flexure to the ileum.

women, mean age 25 years, range 19-32) taking no drugs were studied as controls. None had a history of gastrointestinal symptoms or surgery. No patient or control subject had previously undergone an intestinal intubation study of this nature. All subjects gave written consent and the study was approved by the research ethics committee of the City and Hackney Health District.

\section{SMALL INTESTINAL MOTILITY}

A fine $(2.7 \mathrm{~mm}$ diameter $)$ flexible catheter incorporating six miniature electronic strain gauge transducers (Gaeltec, Isle of Skye, UK)

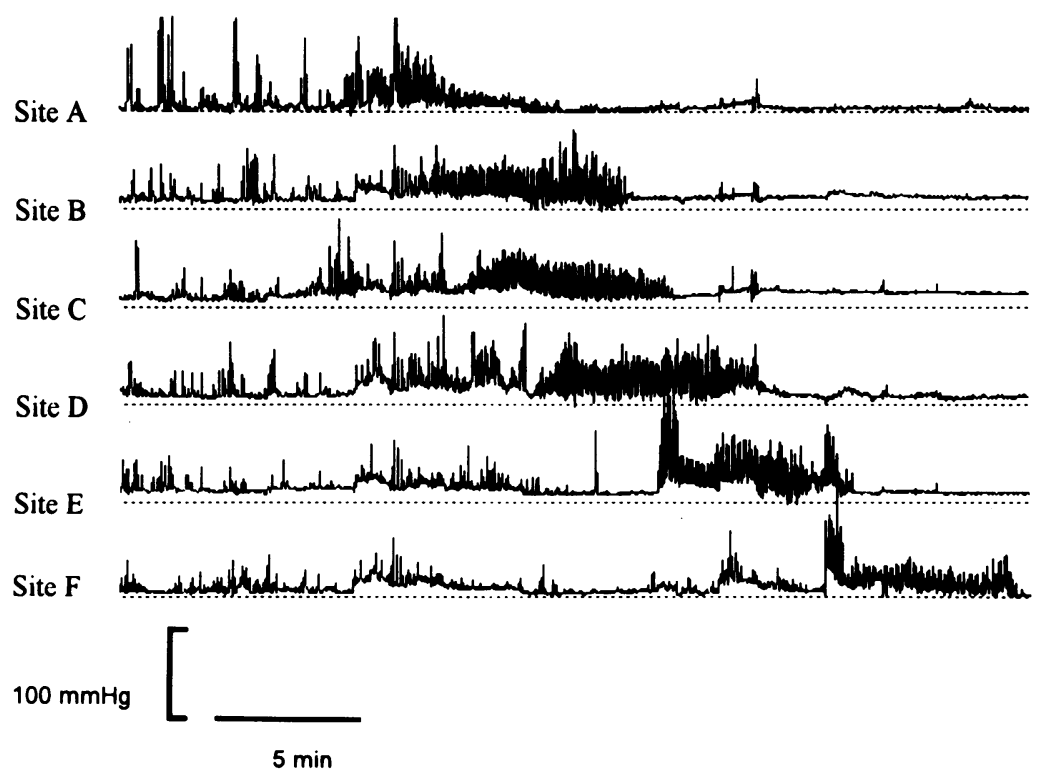

Figure 2: Motility recording from the six intestinal sites. A distally propagating phase III activity front of the migrating motor complex is preceded by irregular phase II activity and followed by quiescence of phase I. Site A represents pressure at the duodenojejunal flexure, sites $B, C, D, E$, and $F$ represent pressure at $15 \mathrm{~cm}, 30 \mathrm{~cm}, 50 \mathrm{~cm}, 70 \mathrm{~cm}$, and $95 \mathrm{~cm}$ aborally. was used to record small intestinal motility. The transducers were sited at $3 \mathrm{~cm}, 28 \mathrm{~cm}, 48 \mathrm{~cm}$, $68 \mathrm{~cm}, 83 \mathrm{~cm}$, and $98 \mathrm{~cm}$ from the distal tip of the catheter. Fasting subjects were nasally intubated with the catheter at 0900 . Once fluoroscopic screening confirmed that the tip of the catheter had traversed the pylorus, a small balloon attached to the tip was inflated with air to facilitate the propagative activity of the intestine in pulling the catheter distally. ${ }^{24}$ The catheter reached its final position when the most proximal transducer was sited at the duodenojejunal flexure (site $\mathrm{A}$ ) and the other five transducers were $15 \mathrm{~cm}$ (site B), $30 \mathrm{~cm}$ (site C), $50 \mathrm{~cm}$ (site D), $70 \mathrm{~cm}$ (site E), and $95 \mathrm{~cm}$ (site F) distal to the duodenojejunal flexure (Fig 1). When this position had been satisfactorily achieved, the length of catheter passed nasally was not much shorter than that used by other investigators to reach the caecum..$^{7816}$ Assuming a similar degree of intestinal sleeving over the catheter, it seems probable that site $F$ was in the ileum. At this point (usually five to seven hours after initial intubation) the balloon was deflated, any redundant catheter was withdrawn from the stomach, and the catheter secured to the face with tape. Recording of small intestinal motility then began, with pressure sampling at 8 hertz. Data were stored digitally in a portable lightweight recorder (7-MPR recorder, Gaeltec Ltd, Isle of Skye, UK) carried in a holster over the subject's shoulder.

Subjects were fully ambulant but were discouraged from taking vigorous exercise because we have previously found that intense physical activity masks the intestinal intraluminal pressure recording with external pressure artefact. Subjects spent the night in a comfortable single room and recording of motility continued until the following morning. Throughout the 16-18 hour study subjects were not allowed to eat, but small amounts of clear fluids were permitted. Subjects were asked to record in a diary episodes of sleeping, awakening, defecation, fluid ingestion, and any IBS symptoms or unpleasant experiences. At these times, subjects also pressed an event button on the recorder, which inserted a mark on the motility record. After completion of each recording, data were transferred from the memory of the recorder to a computer for graphic display and analysis.

\section{ANALYSIS OF MOTILITY}

Analysis was performed without prior knowledge of whether control or IBS data were being studied. Patterns of motor activity were analysed visually (Fig 2). The activity front or phase III of the MMC was recognised as at least three minutes of uninterrupted phasic contractions at the maximum rate for that intestinal site, followed by motor quiescence (phase I). MMC cycle length or periodicity was defined as the time interval between the onset of successive phase III fronts recorded at site B in the proximal jejunum. This site was chosen for calculation of periodicity because phase III fronts are recorded maximally in the proximal jejunum. ${ }^{8}$ The percentage contribution of phase I (quiescence), phase II (irregular contractile activity), and 
TABLE I Percentage duration of each phase of migrating motor complex cycles recorded in proximal jejunum (site B). Values are mean (SEM)

\begin{tabular}{lllr}
\hline & Phase I (\%) & Phase II $(\%)$ & Phase III (\%) \\
\hline Control & & & \\
Day & $15(3)$ & $77(4)$ & $8(1)$ \\
Night & $72(2)$ & $16(2)$ & $13(2)$ \\
IBS & $12(4)$ & $80(6)$ & $8(2)$ \\
Day & $75(3)$ & $14(3)$ & $11(1)$ \\
Night & & & \\
\hline
\end{tabular}

TABLE II Circadian variation in propagation velocity of phase III activity fronts between adjacent sites in small intestine

\begin{tabular}{|c|c|c|c|c|c|}
\hline & \multicolumn{5}{|l|}{ Sites } \\
\hline & $A-B$ & $B-C$ & $C-D$ & $D-E$ & $E-F$ \\
\hline \multicolumn{6}{|l|}{ Control } \\
\hline $\begin{array}{l}\text { Day }(\mathrm{cm} / \mathrm{min}) \\
\text { Night }(\mathrm{cm} / \mathrm{min})\end{array}$ & $\begin{array}{l}6 \cdot 3(0 \cdot 9) \\
4 \cdot 9(0.6)\end{array}$ & $\begin{array}{l}4 \cdot 5(0 \cdot 5) \\
3 \cdot 7(0 \cdot 5)\end{array}$ & $\begin{array}{l}3.9(0.4) \\
3.8(0.4)\end{array}$ & $\begin{array}{l}3 \cdot 4(0.4) \\
3 \cdot 0(0 \cdot 3)\end{array}$ & $\begin{array}{l}2 \cdot 3(0 \cdot 3) \\
3 \cdot 0(0 \cdot 5)\end{array}$ \\
\hline $\begin{array}{l}\text { Day }(\mathrm{cm} / \mathrm{min}) \\
\text { Night }(\mathrm{cm} / \mathrm{min})\end{array}$ & $\begin{array}{l}7.2(0.8) \\
5.9(0.8)\end{array}$ & $\begin{array}{l}6.8(1.3) \\
3.8(0.6)\end{array}$ & $\begin{array}{l}3.6(0.4) \\
2.7(0.2)\end{array}$ & $\begin{array}{l}2.5(0.4) \\
3.0(0.5)\end{array}$ & $\begin{array}{l}3.0(0.4) \\
2.8(0.2)\end{array}$ \\
\hline
\end{tabular}

Values are mean (SEM). Site A represents sensor at duodenojejunal flexure, sites B, C, D, E, and F represent sensors $15 \mathrm{~cm}, 30 \mathrm{~cm}, 50 \mathrm{~cm}, 70 \mathrm{~cm}$, and $95 \mathrm{~cm}$ aborally.

phase III to MMC cycles at the proximal jejunum (site B) was calculated. To qualify as phase I, no more than three single contractions $>15 \mathrm{~mm} \mathrm{Hg}$ over a 10 minute period were permitted. Irregular motor activity was otherwise considered phase II. The propagation velocity of phase III between adjacent sensors was calculated by dividing the distance between sensors by the time taken to pass from one sensor to the next. The duration of each activity front at each sensor was measured from the onset of regular contractions to quiescence. The maximum contractile rate during phase III at each site was measured. The extent to which each phase III migrated aborally, and the percentage of phase III fronts originating at sites beyond site $\mathrm{B}$ were noted.

Computer assisted analysis was used to calculate a motility index for non-phase III - (that is, combined phase I and II) activity in the proximal jejunum (site B). Motility index was calculated as:

mean amplitude of contraction $(\mathrm{mm} \mathrm{Hg}) \times$ mean duration $(\mathrm{min}) \times$ no of contractions time (min)

Contractile waves $<15 \mathrm{~mm} \mathrm{Hg}$ above the current baseline that might represent respiratory excursion were excluded from the motility index calculation. Simultaneous contractions seen at all sensors as a result of artefacts such as coughing were similarly excluded from analysis.

Phase II was scrutinised for the presence of patterns such as discrete clustered contractions. ${ }^{72}$ Discrete clustered contractions were defined as rhythmic bursts of 3-10 phasic contractions at the slow wave frequency for that intestinal site lasting less than two minutes. Each burst was preceded and followed by at least one minute of quiescence.

MMCs recorded during the day were compared with those occurring at night (2300-0500). Evidence for patterns or changes in the pressure record coinciding with events including IBS symptoms recorded by subjects was sought. Such patterns of motility were considered as being coincident if they occurred within two minutes of patients' symptoms.

\section{OROCAECAL TRANSIT TIME}

On a separate occasion, orocaecal transit time was measured after an overnight fast and a $20 \mathrm{ml}$ mouthwash with $0.2 \% \mathrm{wt} / \mathrm{vol}$ chlorhexidine gluconate. End expiratory breath samples were analysed before and at 10 minute intervals after ingestion of $20 \mathrm{ml}(13.4 \mathrm{~g})$ lactulose for hydrogen concentration (Hydrogen monitor, GMI Medical Ltd, Renfrew, UK). Orocaecal transit time was defined as the time elapsed between lactulose ingestion and a sustained $(>10 \mathrm{ppm}$ above baseline) rise in breath hydrogen.

\section{STATISTICAL ANALYSIS}

Data are expressed as mean (SEM). Statistical significance was assessed using analysis of variance and Student's $t$ tests for paired and unpaired data. To assess the correlation of patients' symptoms with motility patterns, recordings were divided into five minute time epochs, and each epoch categorised as a specific motility phase. $\chi^{2}$ test with Yates's correction was then applied to assess occurrence of symptoms during motility phases.

\section{Results}

The total recording time was 136 hours in the eight IBS patients $(17 \cdot 0(0 \cdot 3) \mathrm{h} /$ patient $)$, and 202 hours in the 12 control subjects $(16.8(0.3) \mathrm{h} /$ subject). The volume of clear fluid ingested over each 16-18 hour recording was 480 (40) $\mathrm{ml}$ in IBS patients and $450(35) \mathrm{ml}$ in controls.

\section{CHARACTERISTICS OF MMC CYCLES}

There were 97 complete MMCs in the patient recordings and 135 complete MMCs in the
Figure 3: Propagation velocity of phase III between adjacent pairs of sensors in irritable bowel syndrome (IBS) patients and controls. Site $A$ is the duodenojejunal flexure. Sites $B, C, D, E$, and $F$ are $15 \mathrm{~cm}, 30 \mathrm{~cm}, 70 \mathrm{~cm}$, and $95 \mathrm{~cm}$ aboral to site $A$. 


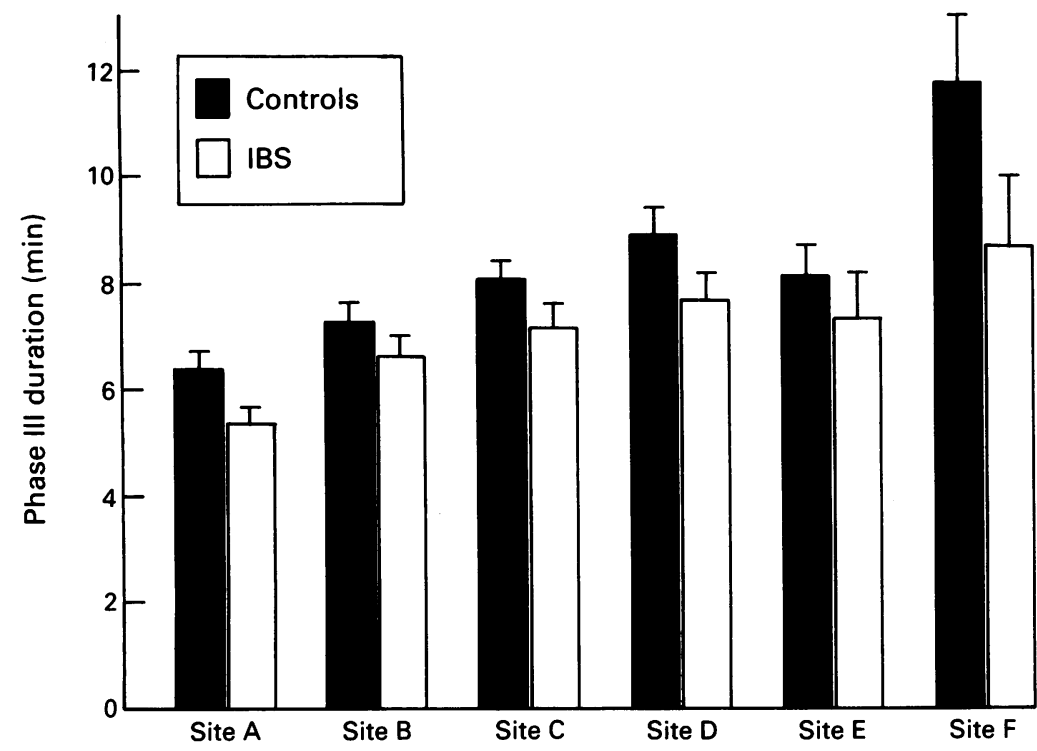

Figure 4: Duration of phase III at each recording site in irritable bowel syndrome (IBS) patients and controls. Site $A$ is the duodenojejunal flexure. Sites $B, C, D, E$, and $F$ are $15 \mathrm{~cm}$, $30 \mathrm{~cm}, 50 \mathrm{~cm}, 70 \mathrm{~cm}$, and $95 \mathrm{~cm}$ aboral to site $A$.

control recordings. Overall MMC periodicity at the proximal jejunum (site B) was 76 (4) $\mathrm{min}$ in the control subjects and 80 (6) $\mathrm{min}$ in the IBS patients. Within the control subjects the nocturnal MMC periodicity of 68 (4) $\mathrm{min}$ was shorter than the diurnal MMC periodicity of 85 (7) $\min (\mathrm{p}<0.05)$. Similarly in the IBS patients, the nocturnal MMC periodicity of 67 (5) $\mathrm{min}$ was shorter than the diurnal periodicity of 92 (10) $\min (\mathrm{p}<0.05)$. There were no differences, however, between the controls and the IBS patients when comparing the respective overall, diurnal or nocturnal periodicities of the two groups. During the day, periodicity of MMC cycles during which fluids were ingested did not differ from those during which subjects were strictly fasted.

The relative contributions of phases I, II, and III to MMC cycles did not differ between control subjects and IBS patients (Table I). In both groups there was a circadian reversal of the relative contributions of phases I and II $(p<0.01)$, so that the dominance of phase II by day was replaced by phase I at night.

TABLE III Maximum phase III contractile rate at each small, intestinal recording site

\begin{tabular}{llllllr}
\hline & Site $A$ & Site $B$ & Site $C$ & Site $D$ & Site $E$ & Site $F$ \\
\hline Controls (contractions/min) & $11 \cdot 0(0 \cdot 2)$ & $10 \cdot 8(0 \cdot 2)$ & $10 \cdot 7(0 \cdot 2)$ & $10 \cdot 5(0 \cdot 1)$ & $10 \cdot 3(0 \cdot 2)$ & $9 \cdot 9(0 \cdot 2)$ \\
IBS (contractions/min) & $11 \cdot 4(0 \cdot 2)$ & $11 \cdot 0(0 \cdot 1)$ & $10 \cdot 8(0 \cdot 2)$ & $10 \cdot 6(0 \cdot 1)$ & $10 \cdot 4(0 \cdot 1)$ & $10 \cdot 1(0 \cdot 2)$
\end{tabular}

Values are mean (SEM). Site A represents sensor at duodenojejunal flexure, sites B, C, D, E, and F represent sensors at $15 \mathrm{~cm}, 30 \mathrm{~cm}, 50 \mathrm{~cm}, 70 \mathrm{~cm}$, and $95 \mathrm{~cm}$ aborally.

TABLE IV Mean amplitude of phase III contractions at each small intestinal site

\begin{tabular}{lllllll}
\hline & Site $A$ & Site B & Site $C$ & Site D & Site $E$ & Site $F$ \\
\hline Controls (mm Hg) & $30 \cdot 9(1 \cdot 4)$ & $34 \cdot 1(1 \cdot 2)$ & $35 \cdot 9(1 \cdot 0)$ & $36 \cdot 7(1 \cdot 2)$ & $38.9(1 \cdot 3)$ & $39 \cdot 4(1.9)$ \\
IBS (mm Hg) & $32 \cdot 2(1 \cdot 7)$ & $34 \cdot 3(2 \cdot 2)$ & $33.9(2 \cdot 1)$ & $36 \cdot 3(2 \cdot 5)$ & $38 \cdot 3(3.9)$ & $41 \cdot 6(1 \cdot 5)$ \\
\hline
\end{tabular}

Values are mean (SEM). Site A represents sensor at duodenojejunal flexure, sites B, C, D, E, and F represent sensors at $15 \mathrm{~cm}, 30 \mathrm{~cm}, 50 \mathrm{~cm}, 70 \mathrm{~cm}$, and $95 \mathrm{~cm}$ aborally.

\section{PHASE III CHARACTERISTICS}

The propagation velocity of phase III activity fronts decreased with aboral progression in both groups. In the control group, propagation velocity slowed from $5.5(0.6) \mathrm{cm} / \mathrm{min}$ in the proximal jejunum to $2.6(0.3) \mathrm{cm} / \mathrm{min}$ in the ileum $(\mathrm{p}<0.01)$ (Fig 3$)$. In the IBS patients, propagation velocity slowed from $6.6(0.5) \mathrm{cm} /$ min in the proximal jejunum to $2.9(0.2) \mathrm{cm} / \mathrm{min}$ in the ileum $(\mathrm{p}<0.001)$. Propagation velocity, however, of MMC phase III between each pair of adjacent sensors was similar in IBS and controls. At night there was a trend for propagation velocities, particularly in proximal regions to be slower than corresponding daytime velocities in both controls and IBS patients (Table II). The differences between the mean velocities, however, over the entire recording segment (sites A-F) of $4 \cdot 3(0 \cdot 3) \mathrm{cm} / \mathrm{min}$ diurnally and $3 \cdot 8(0 \cdot 2)$ $\mathrm{cm} / \mathrm{min}$ nocturnally $(\mathrm{p}=0 \cdot 17)$ in controls, and $4 \cdot 7(0.4) \mathrm{cm} / \mathrm{min}$ diurnally compared with 3.8 $(0.3) \mathrm{cm} / \mathrm{min}$ nocturnally $(p=0.06)$ in IBS patients, did not reach statistical significance.

As phase III activity fronts migrated aborally, their duration at each successive site increased in both IBS and controls (Fig 4). At corresponding sites, however, there were no differences in duration of recorded phase III between IBS and controls. The maximum rate of contraction within phase III decreased gradually with aboral propagation of phase III (Table III). This decrease in maximum contractile rate was seen in both IBS patients and control subjects and there were no differences between the two groups.

The mean amplitude of phase III contraction increased with distal progression (Table IV). In control subjects mean amplitude of phase III contraction was $30.9(1.4) \mathrm{mm} \mathrm{Hg}$ at the duodenojejunal flexure and $39.4(1.9) \mathrm{mm} \mathrm{Hg}$ at the most distal ileal sensor $(\mathrm{p}<0.01)$. In IBS patients there was a similar increase in phase III contractile amplitude from $32.2(1.7) \mathrm{mm} \mathrm{Hg}$ at the duodenojejunal flexure to $41.6(1.5) \mathrm{mm} \mathrm{Hg}$ at the most distal ileal sensor $(p<0 \cdot 01)$. At each intestinal site there was no difference in phase III contraction amplitude between IBS and control subjects. At night the amplitude of phase III contractions was not different from daytime in either controls or IBS.

In controls, $29 \%$ of phase III activity fronts recorded at site $\mathrm{A}$ and seen to propagate to at least the next two sensors (site $C$ ), failed to reach the distal sensor (site F). In IBS the percentage of phase IIIs failing to reach site $F$ was similar at $26 \%$. The proportion of phase III activity fronts originating at a site distal to site $\mathrm{B}$ (and traversing at least two adjacent sensors) was $8 \%$ in controls and $11 \%$ in IBS.

\section{PHASE II FEATURES}

The motility index for diurnal non-phase III activity in control subjects was $5 \cdot 0(1 \cdot 3)$. This was not different from the diurnal motility index of $4 \cdot 2(0 \cdot 9)$ in IBS patients. At night the motility index for non-phase III activity was $1.5(0 \cdot 3)$ in controls and $2 \cdot 1(0.9)$ in IBS patients. These night time motility indexes were significantly $(p=0.01)$ lower than the respective daytime 


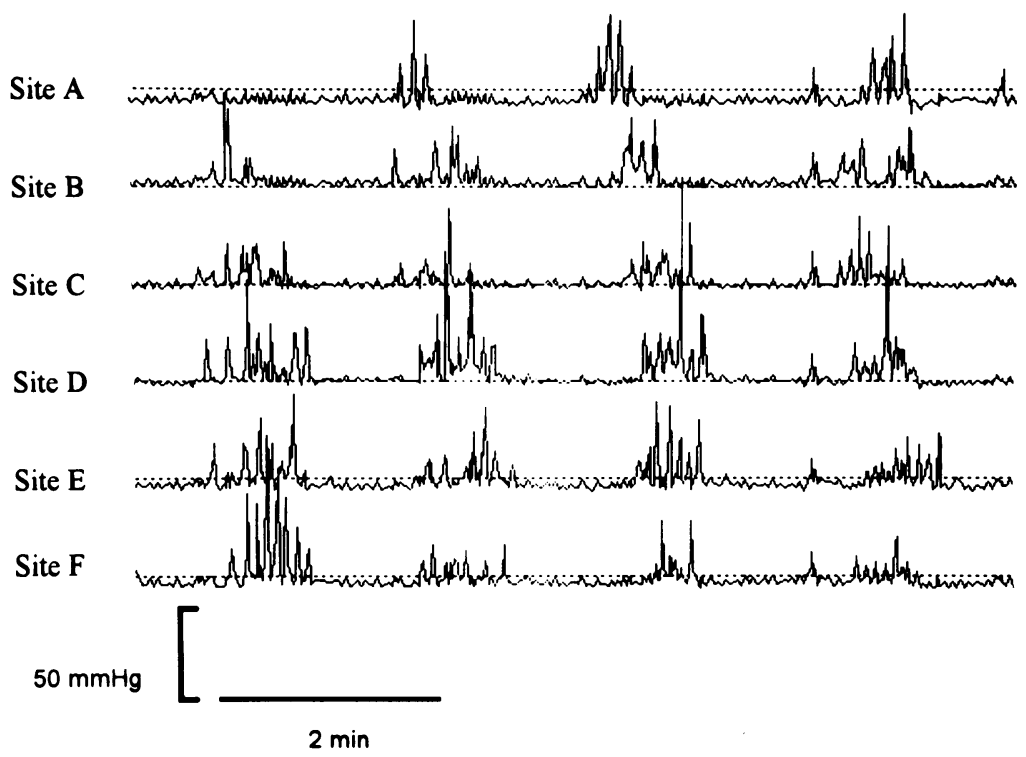

Figure 5: Discrete clustered contractions at all intestinal sites in a control subject. Site $A$ represents pressure at the duodenojejunal flexure, sites $B, C, D, E$, and $F$ represent pressure at $15 \mathrm{~cm}, 30 \mathrm{~cm}, 50 \mathrm{~cm}, 70 \mathrm{~cm}$, and $95 \mathrm{~cm}$ aborally.

motility indexes, reflecting the diminished phase II at night.

Discrete clustered contractions (Fig 5) lasting at least five minutes were seen on at least one occasion in 10 of 12 controls and seven of eight IBS patients. In the control subjects, $14(6) \%$ of diurnal phase II activity at the duodenojejunal flexure was occupied by discrete clustered contractions. In the IBS group, 16 (8) \% of diurnal phase II was occupied by discrete clustered contractions. Discrete clustered contractions were seen maximally at the proximal sensors and infrequently in the ileum (Fig 6). They were less frequent at night in proportion to the decrease in total phase II activity.

PAIN EPISODES

Five IBS patients reported a total of 13 episodes of their typical abdominal pain during the day-

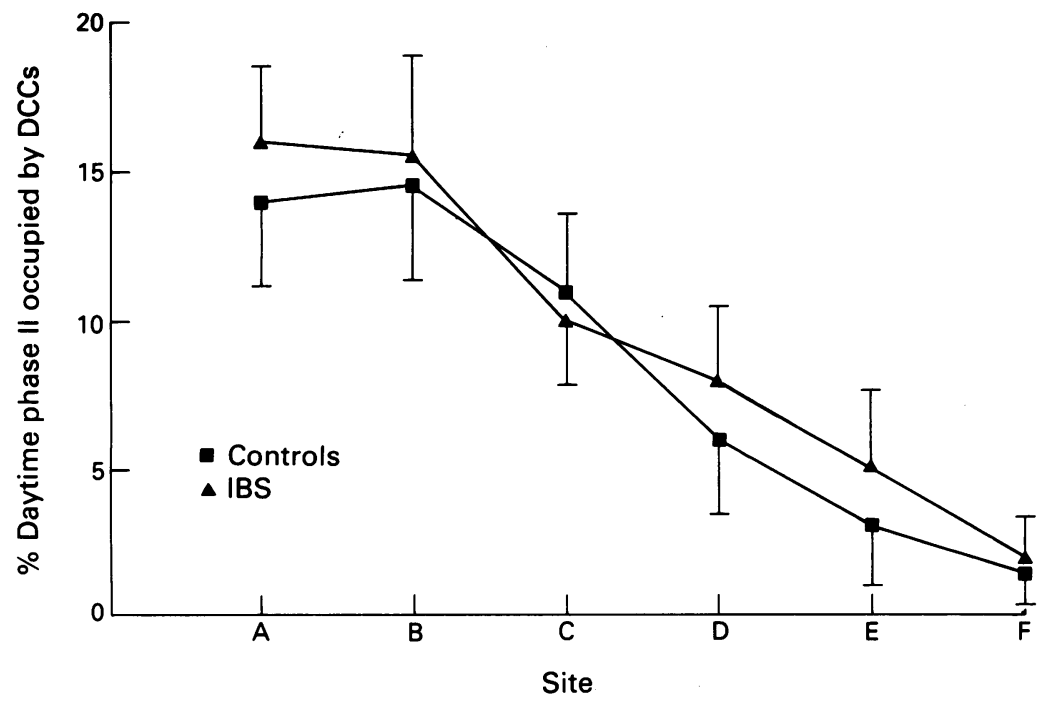

Figure 6: Proportion of diurnal phase II occupied by discrete clustered contractions (DCCs) at each site in the small intestine in irritable bowel syndrome (IBS) patients and controls. Site $A$ is the duodenojejunal flexure; sites $B, C, D, E$, and $F$ are $15 \mathrm{~cm}, 30 \mathrm{~cm}, 50 \mathrm{~cm}, 70 \mathrm{~cm}$, and $95 \mathrm{~cm}$ aboral to site $A$. time recording. No pain episodes occurred at night. Of the 13 episodes, five occurred during propagation of a phase III front, pain being reported during phase III activity at one of the intestinal sites. One pain episode occurred within two minutes of cessation of discrete clustered contractions at sites A and B in the proximal jejunum. The remaining seven episodes occurred while non-specific phase II activity was being recorded at all six intestinal sites. After accounting for the duration of respective phases and the proportion of time at which different phases could be seen at any of the sensors by categorising time epochs, there was no association between pain episodes and small intestinal motility patterns. One control subject also experienced an episode of abdominal pain that occurred while non-specific phase II activity was being recorded at all sensors.

\section{OROCAECAL TRANSIT TIME}

Orocaecal transit time in the control group was 82 (6) minutes. In the diarrhoea predominant IBS group, orocaecal transit time was significantly reduced at $57(9)$ minutes $(\mathrm{p}<0.05)$.

\section{Discussion}

Our method of recording small intestinal motility differs from other studies in that we have recorded motility from sites spanning almost a metre of small intestine in an ambulatory setting. Our findings in the healthy controls are in accordance with previous studies in many respects. MMC periodicity was shorter at night compared with day, ${ }^{6}{ }^{17}$ and was less variable at night. There was a tendency for propagation velocity of phase III to be slower at night, as previously shown by other investigators. ${ }^{26}$ Phase III propagation velocity slowed with aboral progression during day and night periods, although calculated propagation velocity may have been underestimated because of sleeving of the small intestine over the catheter.

The maximum frequency of phasic contraction at a given site was seen during phase III. There was a gradual and consistent decrease in the maximum rate of phase III contractions with aboral progression. This represents the motor component of the gradient in smooth muscle slow wave frequencies. ${ }^{1027} \mathrm{We}$ also noted that the mean amplitude of phase III contractions increased with aboral progression, a finding that has not been previously seen. Phase II occupied most of the motility record by day, but at night phase I dominated the MMC cycle. This circadian variation in phase contribution ${ }^{28}$ has become even clearer as technical refinements in recording equipment permit undisturbed sleep. ${ }^{17}$ MMC cycling is programmed by the enteric nervous system, but modulated by the central nervous system. Phase II activity is associated with central nervous system arousal during waking hours, and can be accentuated by mental stress with consequent delay in appearance of phase III. ${ }^{152930}$ While asleep, the programming of MMCs by the enteric nervous system is uninterrupted by central nervous system activity. Therefore at night phase II is 
minimal and MMC periodicity becomes shorter and more regular. We noted phase III propagation velocity was also less variable at night, suggesting a uniformity of enteric nervous system programming in the absence of central nervous system activity.

Our study has failed to identify abnormalities of fasting small intestinal motility that distinguish diarrhoea predominant IBS from health. Various investigators have looked for small intestinal manometric disturbances in patients with functional gastrointestinal symptoms. Early studies with single radiotelemetry capsules suggested possible motility abnormalities in patients with unexplained abdominal pain. ${ }^{3132}$ These studies, however, used freely migrating sensors, were of comparatively short duration in heterogenous groups of patients, and predated the finding of the interdigestive MMC in humans. After recognition of the human $M M C^{s}$ and its variability, it became clear that prolonged recordings would be of more value. ${ }^{681017}$ Equally important has been defining the patient population under study. Kingham et al studied prolonged jejunal motility in patients with functional abdominal pain using paired radiotelemetric capsules and could not show differences from healthy subjects. ${ }^{33}$ Using similar equipment, sited at the duodenojejunal flexure, Kumar and Wingate saw episodes of irregular phase II like activity associated with pain in patients with IBS. ${ }^{15}$ These episodes could be provoked by mental stress.

Kellow and Phillips recorded small intestinal motility from multiple ports using water perfused catheters, and found that diurnal MMC periodicity was shorter in diarrhoea predominant IBS patients when compared with controls, with phase IIIs propagating further into the ileum. ${ }^{16}$ They also saw an increased incidence of discrete clustered contractions and prolonged propagated contractions in the ileum in IBS patients. These motility patterns were temporarily associated with pain episodes, and occurred both diurnally and nocturnally. A 72 hour ambulatory study using electronic strain gauge transducers straddling the duodenojejunal flexure also reported shortened MMC cyles in diarrhoea predominant IBS. ${ }^{17}$ In this outpatient study, discrete clustered contractions occurred in 11 of 12 IBS patients (most prominently in constipation predominant patients), but in none of the control subjects. The discrete clustered contrations often coincided with pain episodes and never occurred at night. A further study from the same first author, however, reported different findings during prolonged stationary manometry in 20 IBS patients. ${ }^{184}$ Diarrhoea predominant patients had a slower daytime propagation velocity of phase III fronts but no shortening of the MMC period. Constipation predominant patients had longer MMC cycles and lower phase III amplitudes. Discrete clustered contractions were seen mainly in diarrhoea predominant patients. Abdominal sensations had a greater temporal association with duodenal phase III fronts than with phase II activity, and when symptoms did occur during phase II, they were no more likely to occur during discrete clustered contractions than during other phase II activity.
Furthermore, two short (4-6 hour) studies of duodenojejunal manometry failed to identify manometric abnormalities specific to IBS patients. ${ }^{35} 36$ Therefore there is some lack of consistency in reproducing abnormalities of small intestinal motility in IBS.

We have searched for explanations as to why we could not show the aforementioned published abnormalities of small intestinal motility. The IBS patients studied were deliberately chosen because of their symptom predominance ('diarrhoea') and because of the severity of their symptoms; thus we expected any existing small bowel dysmotility to become manifest in this subgroup of patients. Patients were ambulant, and we believe that nasal intubation with a fine catheter in our solid state ambulatory recording system is more comfortable than stationary manometry and its inherent limitation of patient activity or prolonged oral intubation. Food was withheld, as the published abnormalities of small intestinal motility that we wished to reproduce, have been described in the fasting state. We permitted subjects to drink small volumes of fluid to improve comfort and therefore avoid extra stress which might affect motility patterns. We found that ingestion of such fluids neither induced a fed motility pattern nor affected MMC periodicity.

Although not as prolonged as the ambulant study of Kellow et al, ${ }^{17}$ our 16-18 hour ambulatory recordings did obtain additional information from sites in the distal small intestine. The only study recording distal small intestinal motility in IBS reported the positions of recording sites in the terminal ileum in relation to the caecum. ${ }^{16}$ In our study, we cannot be certain of the exact level of the distal sensor (site F) in relation to the ileocaecal sphincter. The catheter length we used was not much shorter than the length of tubing required by others to intubate the caecum..$^{7816}$ Assuming a similar degree of intestinal sleeving over our catheter, our most aboral sensor was in the distal ileum but perhaps not distal enough to record prolonged propagated contractions (a feature of terminal ileal motility), ${ }^{76}$ or variable extent of phase III propagation into the ileocaecal region. ${ }^{16}$

We did not find an increase in discrete clustered contractions in our IBS patients. Only one of 13 pain episodes in the patient group was associated with discrete clustered contractions. We can only conclude that these contractions are a feature of normal fasting motility, ${ }^{72536}$ and neither qualitatively nor quantitatively are they a marker for IBS. It has been suggested that discrete clustered contractions in IBS patients of some studies might represent a motor response to stress and that their matched healthy controls may have been more experienced at intubation studies and therefore less stressed. ${ }^{37}$ The findings of our study in which no subject had previously had a similar test, and therefore in which the stress of intubation was similar in both groups, might seem to be in keeping with this hypothesis. Different types and duration of stress, however, may influence motility in different ways, and a recent study has in fact shown discrete clustered contractions to be suppressed by acute mental stress. ${ }^{38}$ Although it is impos- 
sible to completely avoid any confounding effects of stress, experimental design does seem important when studying motility in IBS. Thus, in the study that most clearly showed a difference in discrete clustered contractions between IBS and controls, ${ }^{17}$ ambulant subjects were studied at home and were allowed to eat freely. In our study, we could not detect manometric changes coinciding with patient symptoms. As our sensors were positioned at several intestinal levels, it can be argued that we would have been more likely to identify motility disturbances associated with symptoms than those studies in which recording was limited to the duodenojejunal region. ${ }^{15} 1734$

Despite the lack of manometric differences in this study, orocaecal transit time was significantly shorter in IBS patients compared with controls, as has been reported previously. ${ }^{49}$ Our technique for measuring orocaecal transit time does not physiologically represent transit of a meal. Lactulose alone does not induce a postprandial motility pattern ${ }^{40}$ and therefore this technique is more relevant in quantifying differences of 'fasting' transit for comparison with the fasting motility patterns recorded in this study. Because gastric emptying is normal in $\mathrm{IBS}^{441} 42$ and liquids start to empty from the stomach almost immediately after ingestion, it seems probable that the differences in orocaecal transit time represent real differences of small intestinal transit.

The explanation for faster transit in the absence of recognisable motility differences in these patients probably lies in our relatively poor understanding of the significance of motility patterns, particularly in relation to transit. Phase III fronts may be comparatively easy to recognise and quantify, but about $80 \%$ of daytime fasting motility is phase II. Recognising patterns within phase II is more difficult, and to identify propagation of single waves, sensors need to be closer together than they were in this study. A motility index is a crude quantitative assessment of phase II activity but is not informative of propagative forces and transit. Similar problems in deciphering postprandial phasic activity have hampered the discovery of any qualitative postprandial motility differences in IBS. Assessments of postprandial motility in IBS patients have only studied its duration and found it either to be normal, ${ }^{16}$ or in the outpatient study when patients ate ad libitum, shortened. ${ }^{17}$ In our ambulatory study we could not identify disturbances of fasting small intestinal motility that serve to distinguish diarrhoea predominant IBS patients from healthy volunteers. We have, however, confirmed that these diarrhoea predominant IBS patients differ from their healthy counterparts with respect to their more rapid small intestinal transit.

1 Read NW. Disturbances in colonic motility. In: Read NW, ed. Irritable bowel syndrome. Oxford: Blackwell Scientific, 1991: 19-23.

2 Lind CD. Motility disorders in the irritable bowel syndrome. Gastroenterol Clin North Am 1991; 20: 279-95.

3 Moriarty KJ, Dawson AM. Functional abdominal pain: further evidence that the whole gut is affected. $B M \mathcal{F}$ 1982; 284: 1670-2.

4 Cann PA, Read NW, Brown C, Hobson N, Holdsworth CD. Irritable bowel syndrome: relationship of disorders in the transit of a single solid meal to symptom patterns. Gut 1983; 24: 405-11.
5 Vantrappen G, Janssens J, Hellemans J, Ghoos Y. The interdigestive motor complex of normal subjects and patients with bacterial overgrowth of the small intestine. f Clin Invest 1977; 59: 1158-66.

6 Thompson DG, Wingate DL, Archer L, Benson MJ, Green WJ, Hardy RJ. Normal patterns of human upper small bowel motor activity recorded by prolonged telemetry. Gut 1980; 21: 500-6.

7 Quigley EMM, Borody TJ, Phillips SF, Wienbeck M, Tucker RL, Haddad A. Motility of the terminal ileum and ileocecal sphincter in healthy humans. Gastroenterology 1984; 87: sphincte

8 Kellow JE, Borody TJ, Phillips SF, Tucker RL, Haddad AC. Human interdigestive motility: variations in patterns from esophagus to colon. Gastroenterology 1986; 91: 386-95.

9 Lindberg G, Iwarzon M, Stål P, Seensalu R. Digital ambulatory monitoring of small-bowel motility. Scand $\mathcal{F}$ Gastroenterol 1990; 25: 216-24.

10 Kerlin P, Phillips SF. Variability of motility of the ileum and jejunum in healthy humans. Gastroenterology 1982; 82: 694 700.

11 Dooley CP, Di Lorenzo C, Valenzuela JE. Variability of migrating motor complex in humans. Dig Dis Sci 1992; 37: 723-8.

12 Szurszewski JH. A migrating electric complex of canine small intestine. Am $\mathcal{F}$ Physiol 1969; 217: 1757-63.

13 Wingate DL. Backwards and forwards with the migrating complex. Dig Dis Sci 1981; 26: 641-66.

14 Sarna SK. Cyclic motor activity; migrating motor complex: 1985. Gastroenterology 1985; 89: 894-913.

15 Kumar D, Wingate DL. The irritable bowel syndrome: paroxysmal motor disorder. Lancet 1985; ii: 973-7.

16 Kellow JE, Phillips SF. Aitered small bowel motility in irritable bowel syndrome is correlated with symptoms. Gastroenterology 1987; 92: 1885-93.

17 Kellow JE, Gill RC, Wingate DL. Prolonged ambulant recordings of small bowel motility demonstrate abnormalities in the irritable bowel syndrome. Gastroenterology 1990; 98: 1208-18.

18 Kellow JE, Eckersley GM, Jones M. Enteric and central contributions to intestinal dysmotility in irritable bowel contributions to intestinal dysmotility
syndrome. Dig Dis $S c i$ 1992; 37: 168-74.

19 Wangel AG, Deller DJ. Intestinal motility in man. III. Mechanisms of constipation and diarrhoea with particular reference to the irritable colon syndrome. Gastroenterolog 1965; 48: 69-84

20 Whitehead WE, Engel BT, Schuster MM. Irritable bowe syndrome. Physiological and psychological differences between diarrhoea-predominant and constipationpredominant patients. Dig Dis Sci 1980; 25: 404-13.

21 Prior A, Maxton DG, Whorwell PJ. Anorectal manometry in irritable bowel syndrome: differences between diarrhoea and constipation predominant subjects. Gut 1990; 31: 45862.

22 Manning AP, Thompson WG, Heaton KW, Morris AF Towards positive diagnosis of the irritable bowel. $B M \mathcal{F}$ 1978; 2: 653-4.

23 Thompson WG, Dotevall G, Drossman DA, Heaton KW, Kruis W. Irritable bowel syndrome: guidelines for the diagnosis. Gastroenterology International 1989; 2: 92-5.

24 Kerlin P, Tucker R, Phillips SF. Rapid intubation of the ileocolonic region of man. Aust NZ F Med 1983; 13: 591-3.

25 Summers RW, Anuras S, Green J. Jejunal manometry patterns in health, partial intestinal obstruction, and pseudoobstruction. Gastroenterology 1983; 85: 1290-300.

26 Kumar D, Wingate D, Ruckebusch Y. Circadian variation in the propagation velocity of the migrating motor complex. Gastroenterology 1986; 91: 926-30.

27 Christensen J, Schedl HP, Clifton JA. The small intestinal basic electrical rhythm (slow wave) frequency gradient in normal men and in patients with a variety of diseases. Gastroenterology 1966; 50: 309-15.

28 Ritchie HD, Thompson DG, Wingate DL. Diurnal variation in human jejunal fasting motor activity. $\mathcal{F}$ Physiol $1980 ; 305$ : in hum.

29 McRae S, Younger K, Thompson DG, Wingate DL. Sustained mental stress alters human jejunal motor activity. Gut 1982; 23: 404-9.

30 Valori RM, Kumar D, Wingate DL. Effects of different types of stress and of 'prokinetic' drugs on the control of the fasting motor complex in humans. Gastroenterology 1986; 90 $1890-900$.

31 Horowitz L, Farrar JT. Intraluminal small intestinal pressures in normal patients and in patients with functional gastrointestinal disorders. Gastroenterology 1962; 42: 455-64.

32 Holdstock DJ, Misiewicz JJ, Waller SL. Observations on the mechanism of abdominal pain. Gut 1969; 10: 19-31.

33 Kingham JGC, Bown R, Colson R, Clark ML. Jejunal motility in patients with functional abdominal pain. Gut 1984; 25 : 375-80.

34 Kellow JE, Eckersley GM, Jones MP. Enhanced perception of physiological intestinal motility in the irritable bowel syndrome. Gastroenterology 1991; 101: 1621-7.

35 Soffer EE, Bruck R, Bar-Meir S. The role of short-term multilumen duodenojejunal manometry in patients with intestinal motor dysfunction. Gastroenterol Clin Biol 1988; 12: 123-5.

36 Quigley EMM, Donovan JP, Lane MJ, Gallagher TF. Antrodud duodenal manometry. Usefulness and limitat

37 Quigley EMM. Intestinal manometry - technical advances, clinical limitations. Dig Dis Sci 1992; 37: 10-3.

38 Kellow JE, Langeluddecke PM, Eckersley GM, Jones MP, Tennant CC. Effects of acute psychological stress on small- 
intestinal motility in health and the irritable bowel syndrome. Scand 7 Gastroenterol 1992; 27 : 53-8.

39 Corbett CL, Thomas S, Read NW, Hobson N, Bergman I,

Holdsworth CD. Electrochemical detector for breath hydrogen determination: measurement of small bowel transit time in normal subjects and patients with the irritable bowel syndrome. Gut 1981; 22: 836-40.

$40 \mathrm{Di}$ Lorenzo C, Dooley CP, Valenzuela JE. Role of fasting gastrointestinal motility in the variability of gastrointestinal transit time assessed by hydrogen breath test. Gut 1991; 32: $1127-30$.

41 Acharya U, Waite N, Howlett P, Tanner AR, Smith CL. Failure to demonstrate altered gastric emptying in irritable bowel syndrome. Dig Dis $S c i$ 1983; 28: 889-92.

42 Nielsen OH, Gjørup T, Christensen FN. Gastric emptying rate and small bowel transit time in patients with irritable bowel syndrome determined by ${ }^{99 m} \mathrm{Tc}$-labelled pellets and scintigraphy. Dig Dis Sci 1986; 31: 1287-91. 